\title{
LA NOCIÓN DE IMAGINACIÓN EN LOS ESTUDIOS SOCIALES DE RELIGIÓN*
}

\section{Gustavo Andrés Ludueña \\ Consejo Nacional de Investigaciones Científicas y Técnicas - Argentina}

Resumen: Este artículo analiza el poder heurístico de la noción de imaginación para el estudio de la religión. Desde una perspectiva crítica a la distinción durkheimiana entre creencias y prácticas, el trabajo destaca su importancia para comprender las relaciones entre ambas. Para ello, se explora la literatura que empleó esta herramienta conceptual en antropología y otras ciencias sociales. En segundo lugar, se muestra su asociación con lo imaginario y la imagen, así como su condición liminar y creativa para el cambio religioso. Finalmente, dos casos etnográficos ejemplifican el proceso de la imaginación en el campo de la cosmología y la experiencia religiosa.

Palabras clave: cambio, imaginación, invención, religión.

Abstract: This article analyzes the heuristic power of the notion of imagination for the study of religion. From a critical perspective of the Durkheimian distinction of beliefs and practices, the work highlights its importance for understanding the relationships between them. In doing so, literature that employed such a conceptual tool in anthropology and other social sciences is reviewed. Secondly, the association with the image and the imaginary, as well as its liminar and creative condition for the religious change is showed. Finally, two ethnographic cases exemplify the process of imagination in the field of cosmology and religious experience.

Keywords: change, imagination, invention, religion.

* El artículo fue originalmente presentado como conferencia de cierre de las Primeras Jornadas del Núcleo de Estudos da Religião (NER-PPGAS-UFRGS) en el $15^{\circ}$ aniversario de su fundación. Deseo expresar mi agradecimiento por la invitación al evento, así como por las preguntas y comentarios recibidos por parte de Carlos Alberto Steil, Ari Pedro Oro, Arthur Isaia, Emerson Giumbelli y João Rickli. Todos ellos fueron de valor y algunos he podido incluirlos en la presente versión, en tanto que otros esperan una mayor exploración. Finalmente, agradezco también las observaciones de los evaluadores anónimos de este trabajo. Los posibles errores u omisiones en el escrito son de mi entera responsabilidad.

Horizontes Antropológicos, Porto Alegre, ano 18, n. 37, p. 285-306, jan./jun. 2012 


\section{Meditación durkheimiana}

En breve estará cumpliendo su centenario una obra fundante para la sociología del conocimiento, y la antropología y sociología de la religión. Publicada en 1912 por Emile Durkheim (1858-1917), Las Formas Elementales de la Vida Religiosa instaló una definición perdurable de la religión como "hecho social." Sustentado en una pretensión universalista y una etnología de los sistemas totémicos australianos, el trabajo propuso una distinción binaria entre creencias y prácticas religiosas. Este artículo intenta volver sobre esta diferenciación con el fin de explorar sus relaciones más que sus naturalizadas fronteras. Sostendré que lo que acostumbramos entender por imaginación en ciencias sociales conecta estas dos esferas de la realidad, y provee una explicación para el cambio social. Por consiguiente, en lo sucesivo revisaré esta noción con el fin de ensayar una sutura a las distinciones durkheimianas corrientes que -al menos para los que nos desplazamos en este campo- hacemos entre creencias y prácticas religiosas; se trata de una dualidad estructural y estructurante que sigue marcando varias de nuestras pesquisas, y que fue discutida críticamente por María Julia Carozzi (2002) para situaciones de conversión. Presentemos sucintamente la relación entre estos elementos para detenernos luego con más detalle en el análisis de una situación específica.

En el curso de un trabajo de campo en monasterios benedictinos en el 2005, tuve la referencia de un movimiento católico denominado Meditación Cristiana. Si bien me era desconocido y no participaba del núcleo de la investigación, atrajo mi atención la similitud que ciertas creencias y prácticas (e.g., el silencio, la disciplina en la oración, etc.) mostraban con otras que venía observando en establecimientos monásticos. En ese año pude asistir a una de las primeras conferencias dictadas por el líder mundial del movimiento en Buenos Aires. Con sede en el Reino Unido, el padre Laurence Freeman es un monje benedictino que dirige la Comunidad Mundial para la Meditación Cristiana (The World Community for Christian Meditation). Sin embargo, pese a estos contactos, no fue sino hasta mucho después que logré conocer mejor lo que hacían los meditadores. Fue en este marco, precisamente, donde conocí a Alberto.

Él es un hombre de unos 60 años que dedicó buena parte de su vida a distintas actividades apostólicas y catequísticas en una iglesia del Gran Buenos 
Aires. Sabe al detalle todo lo que concierne a su parroquia. Desde hace ya unos años es coordinador de un grupo de meditadores. Por su trayectoria activa como laico, tuvo facilidad para conseguir el uso del baptisterio adyacente al templo como espacio destinado para las reuniones semanales. Pese a su cambiante composición, aquél se conserva en un número más o menos estable de unas diez personas. Congregados en asientos dispuestos en semicírculo, Alberto coloca en el centro una pequeña vela como símbolo de la presencia del Espíritu Santo. Aún cuando enfatiza que no se debe ser católico y ni siquiera religioso para meditar, otro de los integrantes frecuentes -de casi su edad- suele llevar y ubicar en un pequeño altar un crucifijo frente a los concurrentes. La simbología general, a causa de la adscripción del lugar, remite naturalmente a la cosmología católica. En tanto que los objetos refieren a un universo de creencias adscriptas al catolicismo, la práctica meditativa -que, en oposición, se enlaza con ideas no convencionales en el imaginario laicalinduce una distancia simbólica que la identidad grupal resuelve por una referencia a los antecedentes del cristianismo primitivo en esta materia.

El ritual no ostenta reglas que hayan sido formalmente estipuladas por la organización de Meditación Cristiana. Muy por el contrario, con el solo compromiso de meditar no hay otras pautas exigidas habiendo, por lo tanto, una importante libertad litúrgica. ${ }^{1}$ La meditación consiste en lograr un estado de relajación que debe surgir de la combinación de una respiración abdominal lenta y profunda, una cómoda postura corporal, y la repetición mental de una palabra “sagrada” específica a modo de mantra; en este caso, se sugiere el término maranatha. De origen arameo, explica Alberto, significa "ven Señor” y enuncia el verdadero espíritu de esta forma de meditación. Al comienzo, se empieza con una lectura reflexiva de alguna de las obras de John Main (1926-1982); quien fuera un benedictino inglés divulgador de la meditación a partir de sus experiencias en Malasia con swami Satyananda en la década de 1950.

A la lectura sigue la meditación con el acompañamiento de una música que Alberto preparó con un software para hacer arreglos de sonido. La melodía, se podría decir, se asemeja a un estilo newager y se prolonga por unos minutos mientras da inicio la relajación. Sentados con los ojos cerrados, las

\footnotetext{
1 El efecto de este fenómeno se hace más elocuente si lo comparamos con la rigurosidad de un ritual convencional como podría serlo una misa en el mismo catolicismo; donde las oraciones, silencios, gestos y movimientos corporales obedecen a patrones preestablecidos.
} 
manos reposando en las piernas y la columna en posición recta, los meditadores se focalizan completamente en el mantra. ${ }^{2}$ La canción, con las luces ambientales apagadas, marca la apertura de la práctica que se extiende por la siguiente media hora. Allí, la grabación que Alberto preparó -que, según afirmó, nos predispondría mejor para la meditación- dejó oír los toques de una campana que resonó a un paisaje tibetano. En ese punto comenzó a darse un lento reavivamiento similar a un despertar, donde quien lo experimenta lo hace con el tiempo necesario para dedicarlo a volver a la condición usual de vigilia. Alberto se levantó de su banco, con un cuidado calculado para evitar ruidos que pudieran perjudicar el clima, para apagar el equipo de audio y encender las luces. El intervalo de silencio acotado por los acordes sella el acontecimiento meditativo. Estando de pie, seleccionó un fragmento de la Biblia y miró aleatoriamente entre los presentes para escoger un lector. La persona elegida leyó los versículos indicados. Eventualmente él mismo suele comentar, u otro asistente contribuye con un comentario. No hay aquí ninguna fórmula prefijada. Al finalizar la lectura nos levantamos y dispusimos en círculo para la bendición; tomados de las manos se rezó el padrenuestro. Luego, Alberto gira indistintamente para un costado u otro de modo tal de quedar de frente a quien tiene a su lado. Apoyando suavemente las manos en los hombros, o tomándola de los brazos con cierta firmeza, mira a los ojos con una sonrisa afectuosa y clara sensibilidad a quien llama por su nombre. El procedimiento se repite a lo largo de la rueda hasta que la bendición alcanza finalmente a Alberto. El principio que guía esta práctica es que "todos podemos bendecir porque todos somos hijos de Dios," lo que tiende a revalorizar el lugar el laico frente a una función que ha venido siendo tradicionalmente reservada al sacerdote.

¿Qué sucede en este encuentro que se repite, con variantes, semana tras semana?; ¿qué relación vincula las prácticas que puedo observar y realizar con los meditadores, y las creencias que dicen que las sustentan? Y, más significativo, ¿cuál es su conexión con las sutiles modificaciones esbozadas en el ejercicio del libre albedrío litúrgico que caracteriza la meditación? En esta

\footnotetext{
2 La repetición del mantra constituye el acto central de todo el procedimiento de meditación. Llevarlo a cabo es una tarea que presenta dificultades de concentración, tal como se deduce de los comentarios de los practicantes. Alberto sostiene que el mantra contribuye a ganar control sobre el ego que siempre sugiere ideas que distraen la atención. Para explicarlo compara metafóricamente la mente con un árbol repleto de monos, donde cada uno representa un pensamiento que "hace ruido.” Por eso, arguye para garantizar la efectividad de la meditación, “hay que dominar los monos que están en nuestra cabeza.”
}

Horizontes Antropológicos, Porto Alegre, ano 18, n. 37, p. 285-306, jan./jun. 2012 
situación etnográfica, en la cual se reúnen elementos tradicionales del catolicismo y otros que presentan un aire más novedoso, es posible advertir un proceso de invención, creación y exploración que se expresa en una ritualidad que es recreada continuamente en el cruce entre las ideas y las acciones. De nuevo, en su pesquisa de la religión totémica, Durkheim (1993) alumbra una vía para pensar la imaginación que, para la meditación cristiana, puede ser "ritual." Él no sólo introdujo una definición de la religión centrada en la oposición entre lo sagrado y lo profano, y entre las creencias y las prácticas religiosas; también sentó los cimientos para una sociología del conocimiento a partir de las llamadas “categorías de entendimiento” (como las ilustran las nociones de espacio, género, causa, etc.). En esta línea, apuntaría Durkheim, la religión está en la base del saber humano y se genera y organiza en categorías de origen colectivo en las que los sujetos de una sociedad son socializados. Junto a ellas, que serían responsables de condensar las "propiedades más universales de las cosas” y son "casi inseparables del normal funcionamiento del espíritu” (Durkheim, 1993, p. 40), el eximio sociólogo francés demarcó lo que sería una suerte de categorías de segundo orden. Esas "otras nociones son contingentes y móviles; [y] concebimos que puedan faltar en un hombre, en una sociedad o en una época” (Durkheim, 1993, p. 40). Me parece que sobre estas últimas, por su carácter más restringido aunque no menos colectivo $-\mathrm{y}$ contingentes a las singularidades sociales e históricas-, descansa una buena fracción del material empírico con el que lidiamos en los estudios de religión. En particular, a nivel de las representaciones y taxonomías nativas de nuestros interlocutores en el terreno etnográfico. Sin embargo, en este escrito lejos de ceñirme solamente a las representaciones, mi intención es destacar el rol de la práctica religiosa y su vínculo con la imaginación.

En años recientes, numerosos investigadores han venido utilizando este concepto en diferentes áreas de trabajo y con disímiles objetos de estudio. Pese a los divergentes temas de indagación, puede advertirse en ellos una continuidad recurrente que reside en que, como herramienta analítica, la imaginación suministra un poder heurístico para el discernimiento de la articulación entre representaciones y acciones colectivas. En sintonía con esta proposición, sostendré tres afirmaciones en este ensayo. Primero, la práctica social es uno de los dispositivos que activa, tanto como orienta y redirige la imaginación cosmológica (es decir, aquello que en clave durkheimiana comprende el extenso horizonte de lo que conocemos por creencias) y viceversa. Segundo, la 
imaginación a diferencia de la creencia y la práctica resiste a la cosificación porque es, ante todo -como diría Victor W. Turner (1974)-, un proceso que incorpora y es definido por la temporalidad; por esa razón es transversal a las representaciones y a la acción religiosa. Tercero, la imaginación se despliega en una matriz intersubjetiva y es, por eso, de naturaleza social. Para tratar la imaginación presentaré inicialmente antecedentes de su aplicación en ciencias sociales, deteniéndome en el uso concreto que hicieron dos antropólogos (Anderson, 2000; Appadurai, 1996). En segundo lugar, abordaré sus relaciones con las concepciones de imagen e imaginario, las que están sólidamente ligadas con la imaginación. Luego, ofreceré datos de mi propia etnografía en monasterios benedictinos para focalizar dos aspectos que -sin ser los únicos- son de importancia para entender el juego de la imaginación; ellos son la experiencia y la cosmología. Vayamos a algunas de las apropiaciones de la idea de imaginación.

\section{La imaginación en antropología y ciencias sociales}

Por su familiaridad con las funciones mentales, la imaginación se asocia con estudios sobre el pensamiento y las mentalidades, en los cuales la etnología y la sociología como la historiografía incursionaron. Por ejemplo, la historia de las mentalidades perteneciente a la École des Annales y encarada por autores tales como Georges Duby, Jacques Le Goff y Michele Vovelle, así como las interpelaciones acerca de las superestructuras y la conciencia de clase llevadas a cabo por el marxismo inspirado en la Escuela de Frankfurt, son las corrientes reflexivas que se perfilan como predecesores teóricos en el estudio de la imaginación y de los imaginarios. Del otro extremo del Atlántico, la imaginación se vinculó con el problema de la representación etnográfica surgido en los años 60’ y 70' en los Estados Unidos de la mano de la llamada antropología crítica y, más tarde, de la antropología posmoderna. En estos desarrollos igualmente se destacó el empleo analítico de lo imaginario y la difusión en las ciencias sociales del psicoanálisis (Jameson, 1977).

Para la época, Edward Said (2005) habló de "geografías imaginadas” con relación a la percepción cultural de los espacios de Oriente y Occidente, las que definirían las identidades y pertenencias tanto como las discrepancias con los otros. Por otra parte, adoptando elementos del psicoanálisis lacaniano y 
de la teoría poscolonial, Homi Bhabha (2002) recurrió al “imaginario” y a las “comunidades imaginadas" de Benedict Anderson (2000) para aproximarse a las representaciones culturales de las naciones poscoloniales. En la dirección de los estudios etnográficos africanistas, John y Jean Comaroff (1992, 2000), por su lado, exploraron el cambio histórico entre los tshidi de Sudáfrica y sus vinculaciones con la agencia, la cultura y el poder. En su análisis antropológico de la experiencia colonial sudafricana es posible hablar de "imaginación social”, “histórica”, “cultural”, “política” y “subversiva.” En la órbita de la historiografía, Jacques Le Goff (1991) visualizó la temporalidad como "imaginario" para indicar los procesos a través de los que las sociedades conciben el tiempo como momentos excepcionales o catastróficos. Más cerca de nuestras latitudes, Gustavo Lins Ribeiro y Arturo Escobar (2008), en un tono poscolonial similar al de Walter Mignolo (2000), recurren a la "imaginación” de nuevas epistemes localizadas que se caracterizan por estar fundadas en teorías geopolíticamente emergentes de saberes alternativos no hegemónicos. Esta relevancia de los conocimientos localizados fue central en la "imaginación técnica” propuesta por Beatriz Sarlo (1992) desde los estudios culturales, quien exploró la circulación de habilidades prácticas intelectuales en los sectores populares que surgieron como resultado de la alfabetización masiva impulsada a comienzos del siglo XX en la ciudad de Buenos Aires. Un tenor idénticamente amplio registran los trabajos que incorporan stricto sensu la idea de "imaginario"; muchos de ellos vinculados a indagaciones sobre la modernidad, la posmodernidad y el espacio, en especial, el espacio urbano (García Canclini, 1997).

En virtud de la plétora de usos existentes, por lo tanto, sólo referiré a dos empleos del término en antropología, los que acompañaron reflexiones teóricas de procesos sociales e históricos a gran escala. El primero de ellos es el de Benedict Anderson (2000) para el estudio de la nación y el nacionalismo. Según este autor, la nación puede verse como "una comunidad política imaginada” (Anderson, 2000). Anderson recurre a esta estrategia para explicar las formas en las que los estados nacionales comenzaron a pensarse como agregados colectivos territorializados, al tiempo que se veían simultáneamente como unidades culturales con sus propias tradiciones, costumbres y lenguajes. Pero, más aún, fue la relevancia de la "imagen” en sí la que dio a los miembros de la nación una pauta de lo que podría ser un agrupamiento de sujetos que, muy probablemente, nunca llegarían a conocerse en persona. Esto porque, en sus 
palabras, "todas las comunidades mayores que las aldeas primordiales de contacto directo (y quizá incluso éstas) son imaginadas” (Anderson, 2000, p. 24). Algo similar, veremos en otro ítem, sucede con los monjes.

De este modo, la imaginación funciona como proyección de lo ausente, lo incierto o lo que aún no llega; le cabe el rol de anticiparse al devenir. Es decir, como la promesa de un futuro mediato o inmediato que todavía no consigue materializarse en la realidad cotidiana. El objeto de la imaginación es la comunidad, en tanto que el sujeto de la imaginación es la propia nación; por eso se la piensa limitada, soberana y como comunidad. Son los actores, como unidades autónomas, los que imaginan a sus compatriotas como co-sujetos de un colectivo del que ellos son partícipes. Se abre así el juego de identificación de unos con otros como nacionales. La magia de la imaginación, de esta forma, se plasma en la representación de una imagen de unidad abstracta. Se trata de individuos que conciben independientemente un mismo grupo social. En este procedimiento de pensar al conjunto, Anderson (2000) subrayó el rol de los medios de alcance masivo que, como la literatura y el periodismo, o como lo llamó, el “capitalismo impreso,” habrían permitido volcar en el papel la nación imaginada nacida de la conexión de sujetos distantes (Anderson, 2000, p. 47).

Si Anderson destacó el rol de la imaginación en la elaboración histórica de la nación, Arjun Appadurai (1996), por su parte, enfatizó el servicio de la imaginación a la producción de un escenario político posnacional para visibilizar las causas y derivaciones de la modernidad globalizada. En su óptica (Appadurai, 1996, p. 5, traducción mía), “en un mundo poselectrónico la imaginación juega un papel significativamente nuevo.” Eso porque la gente común, y no ya solamente personajes carismáticos, imaginan cómo serán -0 podrían ser- sus propias vidas en otros espacios y tiempos venideros en un ejercicio de abstracción provisoria; tal es el caso, por ejemplo, de las corrientes diaspóricas y migratorias que se desplazan por circuitos transnacionales en busca de un presente y un futuro más promisorio. Segundo, existe un contraste entre imaginación y fantasía. Mientras la fantasía “connota la noción del pensamiento divorciado de los proyectos y los actos, y también tiene un sentido asociado a lo privado y hasta a lo individualista;" la imaginación "posee un sentido proyectivo, el de ser un preludio de algún tipo de expresión, sea estética o de otra índole” (Appadurai, 1996, p. 7, traducción mía). En tercer lugar, hay una distinción entre la imaginación individual y la colectiva; esta última 
generosamente favorecida por la extensión de los medios de comunicación masivos y la cultura de masas (Appadurai, 1996).

En esta tendencia, Appadurai se interesó por los “mundos imaginados” de la era global, resaltando las migraciones a nivel mundial y las tecnologías actuales como los instrumentos que viabilizan el despliegue de lo que llama el "trabajo de la imaginación" (work of the imagination) (Appadurai, 1996). Aquéllas compondrían dilatados desplazamientos a través de los cuales la modernidad consolida la creación de renovadas subjetividades. En este marco globalizado y atravesado por lo moderno, las tecnologías resultantes de la revolución electrónica, como las surgidas en el campo de la computación y la comunicación, serían los dispositivos centrales mediante los que las personas generan ese trabajo de imaginación que produce noveles imágenes del mundo y de uno mismo. En este orden, los paisajes sociales emergentes en esta escena en transformación impulsaron la reconfiguración de identidades a partir de la imaginación de estrategias alternativas de presentación en la vida cotidiana. De esta manera, los flujos de información, de sentidos, personas y objetos, como las diásporas y las rupturas, más que las continuidades y lo estático, caracterizan y motorizan -junto a los cambios tecnológicos- el trabajo de la imaginación. El uso de la noción de imaginación apunta tanto a comprender un cambio acelerado, complejo y global, como a destacar la realización de imágenes que surgen de contextos socioculturales específicos, y que son compartidas por los miembros de colectivos sociales desterritorializados. En resumen, el trabajo de la imaginación acompañaría la acomodación a paisajes étnicos, ideológicos, tecnológicos, financieros y mediáticos (Appadurai, 1986, 1996).

Al igual que Anderson, Appadurai examina el trabajo de la imaginación en una proporción macroscópica e informa poco acerca de los mecanismos microsociológicos que nutren el desarrollo de los imaginarios; y, justamente, son los que permiten imaginar una realidad-otra como descubriremos en los religiosos monásticos. Asigna a la imaginación una novedad histórica que, como disparadora de invención sociológica es identificable en otros contextos sociales y no sólo en procesos culturales globales contemporáneos. Por otro lado, confiere a los medios de comunicación masiva un rol protagónico en la difusión de imágenes y en la conformación de los paisajes imaginarios, eso a pesar de reconocer la variabilidad de las traducciones locales de aquellas imágenes. Puede decirse que, no obstante, un aspecto de interés traído por Appadurai es el de la imaginación "como práctica social” 
(Appadurai, 1996, p. 31), en especial, cuando "puede ser el combustible para la acción” (Appadurai, 1996, p. 7, traducción mía). Si bien este atributo no constituye una novedad, cierto es que esa acción está mediada por imágenes sociales que condensan deseos colectivos alimentado, por esa razón, la acción en determinado cauce.

\section{La imaginación y los imaginarios}

Una característica que puede advertirse en las definiciones anteriores es que la imaginación no constituye un lugar utópico para la evasión o la fantasía. Por el contrario, se sitúa más cerca del acontecer que de la ilusión; puede sostenerse que, centrados en el imperativo de lo real, se presentan tres rasgos en estas indagaciones que se desplazan en esa trayectoria. Uno es la exaltación que cada enfoque (Anderson, 2000; Appadurai, 1996) ensaya sobre la dimensión innovadora del acto de imaginar, como muestra la imaginación ritual de los meditadores cristianos. Esta consideración aleja la imaginación del supuesto que asume un sujeto alienado y dominado por una falsa conciencia. El segundo punto consiste en su potencial para cristalizarse en la forma de un proyecto concreto, como cuando éste implica la invención de escenarios sociales alternativos. El tercer rasgo que parece enfatizarse es el vínculo con la imagen o la representación que, en su forma de conglomerado complejo, constituye el imaginario como tal. Tanto en estas perspectivas como en otras que por razones de espacio no puedo abordar, la imaginación se ha venido mostrando como un término de una notable plasticidad conceptual para referir, por ejemplo, a una imaginación "sociológica” (Rose, 1969; Wright Mills, 1961), “dialógica” (Bakhtin, 1981), “política” (Comaroff; Comaroff, 2000; Hall, 1987), “histórica” (Comaroff; Comaroff, 1992), “poética” (Bachelard, 2000), “creativa” (Turner, 1974) o, como la denominó Gilbert Durand (1971) por su alusión a una cualidad mental, "simbólica."

Podemos entonces entender la imaginación, más que el imaginario en sí -al decir de Cornelius Castoriadis (2007)-, como la función operativa que está por detrás de las nociones de segundo orden (Durkheim, 1993) mencionadas al inicio del artículo. Esta aproximación, nos sitúa frente a la imaginación al modo en que lo hace Paul Ricoeur (1994, 2000). Como la adopto en este trabajo, la imaginación -por su naturaleza liminar- puede evocar sentidos 
y sensaciones, como proyectar realidades posibles. Ricoeur identificó cuatro usos históricamente generales de la imaginación, dos de los cuales remiten a cosas reales y otros dos a cosas irreales. De los primeros, un empleo indica objetos ausentes "pero existentes en otro lugar," en tanto que otro señala entidades que, con existencia propia, toman "el lugar de las cosas que representan” (Ricoeur, 2000, p. 199, énfasis del autor). Por otra parte, acerca de lo irreal, la imaginación puede remitir a "ficciones que no evocan cosas ausentes, sino cosas inexistentes” (e.g., sueños, novelas, etc.); por último, sea ausentes o inexistentes, están las imágenes que "hacen creer en la realidad de su objeto" (Ricoeur, 2000, p. 199).

Para los estudios de la religión, es factible afirmar, se manifiesta una correlación más o menos regular entre prácticas y representaciones; relación que Durkheim y Mauss supieron captar. Pero que también lo hizo Karl Marx en los textos donde abordó la relación entre imaginarios y acciones políticas, como sucede en el 18 Brumario de Luis Bonaparte. Creo que aquí la reificación comentada por Carozzi (2002) respecto de la separación entre creencias y prácticas puede evadirse por la imaginación, ya que escapa a la cosificación por su índole procesual y responde más a la condición de verbo que a la de sustantivo. En esta línea, la visión crítica de Vincent Crapanzano (2005, p. 367) del empirismo antropológico que intenta limitarse a los hechos fácticos, apunta a denunciar cómo se "ignora uma importante dimensão da experiência.” Dicho de otra manera, "[é] o artifício de factualidade, de nosso empirismo, de nosso realismo, pelos quais nos cegamos a nós mesmos -muitas vezes, por meio de disparatadas metodologias da verdade e de ingênuas filosofias positivistas” (Crapanzano, 2005, p. 366). Este autor propone una epistemología alternativa que incorpore la imaginación -o lo que llama "horizontes imaginativos"como estrategia incluyente de los silencios, transiciones, indefiniciones, etc., las que son habituales a la vida social. Estos interludios de pasaje usualmente se resisten a ser enunciados y, podríamos agregar, clasificados. Pero todos ellos, sin embargo, pertenecen al ámbito de lo simbólico y de la experiencia. Y es ahí, precisamente, donde es necesario hablar de la imagen como dispositivo de re-presentación.

En este rumbo, Bronislaw Baczko (1999) sitúa la imaginación en el contexto más vasto de los sistemas simbólicos, dado que "no es posible un modo de existencia no simbólico y aún menos un tipo no simbólico de acción” (Ricoeur, 1994, p. 54). En palabras de Durand (1971, p. 9), la conciencia 
humana tiene la capacidad de representarse el mundo de manera directa o indirecta, siendo una instancia en la que "la cosa no puede presentarse en 'carne y hueso' a la sensibilidad”; pero, aún en estos casos, es posible que “el objeto ausente se re-presente ante [la conciencia] mediante una imagen, en el sentido más amplio del término” (Durand, 1971, p. 10, énfasis del autor).

La imagen oscila entre la percepción sensible absoluta de la cosa y la ausencia categórica del objeto imaginado, sólo aprehensible por las imágenes que los sujetos se forman de él. Es ese, ciertamente, el espacio de la imaginación simbólica que se presenta "cuando el significado es imposible de presentar y el signo sólo puede referirse a un sentido, y no a una cosa sensible” (Durand, 1971, p. 11-12, énfasis del autor). En otros términos, la imaginación habla en el lenguaje del, y a través del, símbolo, que "evoca [...] algo ausente o imposible de percibir" (Durand, 1971, p. 13, énfasis del autor). Igualmente para Castoriadis (2007, p. 204), el imaginario es "la capacidad elemental e irreductible de evocar una imagen.” Por este motivo, la imaginación juega siempre el juego de la evocación, para trocar una presencia abstracta -i.e., no presente- en otra sensible -i.e., re-presentada-; para este autor (Castoriadis, 1998, p. 274), "la imaginación es el poder (la capacidad, la facultad) de hacer aparecer representaciones, procedan o no de una incitación interna.” Así, aquélla es capaz de representar en la conciencia el conjunto de deseos, esperanzas, temores, recuerdos, etc., señaladas por Baczko (1999), quien, dicho sea de paso, ubica en una relación dialéctica la imaginación y la experiencia. Asimismo, sostiene que el imaginario puede ser tanto "un esquema colectivo de interpretación de las experiencias" como un instrumento que "conduce a los individuos en una dirección común” (Baczko, 1999, p. 30, énfasis mío); eso sucedió, se verá seguidamente, en la mutación de una clase de monasticismo basada en la misión externa a otra anclada en el retiro del mundo. En sus palabras,

El dispositivo imaginario asegura a un grupo social un esquema colectivo de interpretación de las experiencias individuales tan complejas como variadas, la codificación de expectativas y esperanzas así como la fusión, en el crisol de una memoria colectiva, de los recuerdos y de las representaciones del pasado cercano o lejano [...] Al tratarse de un esquema de interpretaciones pero también de valoración, el dispositivo imaginario provoca la adhesión a un sistema de valores e interviene eficazmente en el proceso de su interiorización por los individuos, moldea las conductas, cautiva las energías y, llegado el caso, conduce a los individuos en una dirección común (Baczko, 1999, p. 30, énfasis mío).

Horizontes Antropológicos, Porto Alegre, ano 18, n. 37, p. 285-306, jan./jun. 2012 
De este modo, el imaginario no solamente se edifica sobre la experiencia sino que la moldea; de alguna forma, opera -siguiendo la clásica expresión de Claude Lévi-Strauss (1988)- como un "pensamiento concreto" de clasificación, codificación y percepción del acontecer imponiéndole una "exigencia de orden.” En frecuencia con esta afirmación, “[1]a imaginación [...] es por eso mismo poder de organización. La formación $a b$ ovo de una 'imagen’ deviene ipso facto posición y puesta en relación de 'elementos'” (Castoriadis, 1998, p. 307). En una relación intrínseca con la experiencia, la imaginación tampoco se divorcia de la praxis, como fue expuesto por otros autores (Castoriadis, 1998, 2007; Ceriani Cernadas, 2008; Ricoeur, 1994, 2000; Ludueña, 2009), sino que presenta "una función proyectiva que pertenece al dinamismo mismo del actuar” (Ricoeur, 2000, p. 206). Es decir, lo imaginado -o, en otras palabras, el "imaginario efectivo" (Castoriadis, 2007)-, en tanto producto de la imaginación, está genéticamente ligado a la acción dado que, apropiaciones mediante, puede dirigir a los sujetos en los márgenes de un recorrido compartido; aunque, veremos, lo contrario es viable cuando la imaginación colectiva, o la de actores específicos, conduce a resultados imaginados divergentes por nutrirse de imágenes que sugieren formas sociales distintas. Analicemos estas cuestiones a partir de una situación de conflicto ocurrida entre religiosos benedictinos a comienzos de la década de 1970.

\section{Experiencia y cosmología monástica}

$\mathrm{Al}$ igual que el resto de las órdenes y congregaciones religiosas llegadas de Europa a la Argentina durante el último tercio del siglo XIX, los benedictinos se prestaron a colaborar con la iglesia local en distintas actividades misionales (Ludueña, 2010). Esta forma de inserción en la sociedad sentó tradiciones y perfiles religiosos en las experiencias de vida consagrada de hombres y mujeres hasta la mitad de la centuria subsiguiente. En ese momento, varios de estos principios comenzaron a ser objeto de revisión. El benedictino fue sólo un caso entre muchos otros y, como el resto, sintió los vientos de innovación que atravesaron el catolicismo. A partir de los años 60’, una fracción considerable de los monjes argentinos iniciaron un cambio que se apoyaba en una mirada renovada de los llamados Padres del Desierto -también rescatados por Meditación Cristiana-; ello daría forma a posteriori a un "modelo 
monástico patrístico” (Ludueña, 2008). Aquéllos fueron “[1]os primeros cristianos que se retiraron al desierto [y] no deseaban otra cosa sino vivir en la mudez expectante de la creación el diálogo del silencio” (Sáenz, 1967, p. 14, énfasis del autor). Uno de los promotores locales de este monacato, y otros muchos que como él incursionaron en este proyecto en las afueras de la ciudad de San Miguel de Tucumán, estaba convencido de que esta inclinación permitía vislumbrar "el carácter necesariamente escondido y casi incomprensible de tal régimen de vida. Su lenguaje es un lenguaje de silencio” (Sáenz, 1967, p. 14-15). Las figuras que a su juicio podían ser ensalzadas en esa empresa eran san Antonio de Egipto (251-356) -como el “primer monje”- y san Benito de Nursia (480-547) -como el fundador mítico de la Orden Benedictina a la que pertenecía-. Ambos impulsores del monasticismo, en su forma eremítica y cenobítica, en tiempos de la iglesia primitiva. Además de la renuncia, el silencio y la soledad como experiencia religiosa, ellos compartían la vivencia del desierto; el cual lejos estaba de ser un vacío neutral de contenidos significantes. De este modo, el desierto -metafórico- solitario y silencioso del cerro tucumano, en el que otros con idéntica concepción de lo que la experiencia monacal debería ser se asentaron, metaforizaba el desierto de los Padres; entre los que tanto Antonio -en Egipto- como Benito -en Subiaco, Italia- estaban incluidos. Pero esta metaforización no era un como sino un es, alegaría Ricoeur (1980). En otras palabras,

[de la] conjunción entre ficción y redescripción concluimos que el 'lugar' de la metáfora, su lugar más íntimo y último, no es ni el nombre ni la frase ni siquiera el discurso, sino la cópula del verbo ser. El 'es' metafórico significa a la vez ‘no es’ y 'es como'. Si esto es así, podemos hablar con toda razón de verdad metafórica, pero en un sentido igualmente 'tensional' de la palabra 'verdad'. (Ricoeur, 1980, p. 15).

Mientras “[l]a comparación dice 'esto es como aquello'; la metáfora: ‘esto es aquello’. Por tanto [...] cualquier metáfora, es una comparación implícita, en la medida en que la comparación es una metáfora desarrollada” (Ricoeur, 1980, p. 43, énfasis del autor). En suma, en la campaña de estos monjes persistió la confección de un desierto mítico al cual se aludía recurrentemente. De modo parecido en el que el desierto arcaico se constituía en un "modelo para” la cimentación del páramo buscado en el presente, éste 
se convertía en "modelo de" aquel espacio mítico fundacional y referencial (Geertz, 1987). Esta lógica simbólica se difundió a otras comunidades religiosas y comenzó a regir las próximas mutaciones en el paradigma monástico; ahora, de orientación patrística (Ludueña, 2008).

La opción por el desierto, por otro lado, fue algo que debía asumirse con fuerte compromiso. El monasterio, de acuerdo a la "novedosa" forma en que empezaba a ser concebido, sintetizaba estos valores primigenios que giraban en torno a la imitación del desierto de los ascetas cristianos. Esa imagen que junto a otras orientaba esos cambios, por consiguiente, no era un mero "contenido psíquico" sino que se asociaba a una "estructura intencional” (Sartre, 1973, p. 117) que encausaba la acción por un camino más o menos delineado. Pero no era un desierto que se vivía en soledad; muy por el contrario, como señalaban quienes estaban involucrados en este estilo de religiosidad, "el monasterio es, en realidad, una familia [...] pero este espíritu de familia penetra todos los pequeños imponderables que hacen el día de los hombres" (Sáenz, 1967, p. 45, énfasis mío). El proceso de imaginación desplegado dio origen a un movimiento que hizo tanto del desierto como de la convivencia en la soledad y el silencio, el "ideal” por excelencia de este proyecto. El plan no estuvo libre de criticismos hacia consecuencias de la modernidad como, por ejemplo, la pobreza; pero, también, hacia lo que se juzgaba como falta de compromiso y solidaridad, o la tendencia a vivir solamente la inmediatez del presente.

Además de la residencia en común, se puntualizó el "trabajo manual” como uno de los requisitos para alcanzar una consagración monástica óptima. Este hincapié refería a un interés por "transformarse de día en día," se afirmaba, en "imagen y semejanza” de Cristo -quien, a la sazón, era el arquetipo a seguir-. La introducción del trabajo manual en esta forma de espiritualidad rompía, aún antes de las exhortaciones de aggiornamento encaradas por el Concilio Vaticano II (1962-1965), con una costumbre donde las labores periódicas eran ejercidas por los llamados hermanos legos - es decir, aquellos que no tenían la consagración sacerdotal-. Precisamente, fue un disenso en este punto del trabajo, que encerraba causas ideológicas y políticas de fondo, lo que sostuvo la diferenciación social entre los segmentos enfrentados de arriba y de abajo en el monasterio de Tucumán. Mientras unos -defensores de un programa "social"- buscaban trabajar fuera del establecimiento en un acercamiento con sectores populares aledaños, llegando incluso a emplearse 
como obreros en una fábrica de la zona, los de arriba -fieles al mandato del retiro- promovían el trabajo manual sin salir de los confines del microdesierto simbólico de una atmósfera monástica solitaria. Juntamente con el anterior, la pobreza fue fundamental. Nuevamente, los ascetas resultaron ser los héroes y guías.

Una de las características del trabajo monástico, tal como se practicó en los primeros siglos, fue el de ser un verdadero trabajo de pobres. Los Padres del Desierto tejían juncos y fabricaban canastas; en los primeros monasterios de Egipto se cultivaba la tierra, se trabajaba en la panadería, en la construcción de celdas. (Sáenz, 1967, p. 61).

Ese pasado remoto proveyó el pivote alrededor del que giró la imaginación en torno a lo que "realmente" debería ser un monje. "[L]os primeros monjes," se argumentaba, "querían ser positivamente verdaderos pobres” (Sáenz, 1967, p. 61-62). Ellos, "no hicieron especulaciones muy complicadas sobre [la pobreza], simplemente la practicaron. Volvieron su mirada a Cristo y trataron de conformarse a Él” (Sáenz, 1967, p. 62). Esta modalidad, según reconocían, no podía ser abrazada por todos. La práctica de la pobreza voluntaria, en su intención ascética, fue visualizada como una actividad de elite restringida sólo a elegidos y personificada en la figura del "virtuoso" religioso (Hill, 1973; Silber, 1995; Tambiah, 1977, 1982; Weber, 1996). Para algunos, ya no eran las prestigiosas comunidades benedictinas medievales -como la de Cluny- las que debían alimentar los imaginarios de los religiosos argentinos sino, por el contrario, los monjes de "hace quince siglos" (Sáenz, 1967, p. 62). Con relación a la pobreza se advierte, asimismo, otra diatriba lanzada a la modernidad y, especialmente, al progreso, como uno de sus signos más evidentes. "La pobreza voluntaria, es cierto, es una acusación formal contra todo lo que el progreso desviado de Dios pretende levantar para sustituir a Dios. Es un desprecio de todo lo que el progreso tiene de ídolo” (Sáenz, 1967, p. 65).

No obstante, no se trataba de una negación absoluta del progreso. El criticismo era parcial y se dirigía concretamente contra un tipo de progreso que era percibido como “desviado de Dios” (Sáenz, 1967). Otra de las dimensiones que el emprendimiento patrístico mostró en tensión con la modernidad -en particular, contra el individualismo moderno- fue el de la importancia de la residencia en común de los miembros de la familia monástica que cohabitan 
en el monasterio. ${ }^{3}$ Esta arista ayudó a vigorizar un discurso que apuntaló una identidad monástica que, aludiendo a la vida familiar como sinónimo de solidaridad y convivencia comunitaria (Ludueña, 2008), contestó el paradigma religioso anterior fundado en el ministerio sacerdotal externo.

\section{Conclusión}

El caso estudiado ilustra el modo en que se imaginó una forma alternativa de vida monástica a partir de la focalización sobre categorías específicas que definieron el perfil exacto de una nueva experiencia socio-religiosa. Esto se adiciona a las tres afirmaciones formuladas al principio del escrito. Es decir, la imaginación es y se relaciona con la práctica; responde a una dinámica procesual; y es eminentemente intersubjetiva. Un cuarto rasgo es, por lo tanto, que avanza siguiendo una lógica de fragmentación de la realidad. Las formas sociales imaginadas, independientemente de su escala, se piensan a partir de parcialidades constitutivas que son significativas para los sujetos. Es en este aspecto donde la imaginación manifiesta su más alto grado de operatividad práctica. Aquí, las categorías de segundo orden de las que habló Durkheim (1993) son las de desierto, comunidad, trabajo, silencio y pobreza. Puede alegarse, entonces, que la imaginación procede por partes jerarquizadas que remiten a sistemas nativos de valoración. En los imaginarios existen estructuras de sentido y núcleos semánticos más o menos permeables a la producción de significado o, en palabras de Ricoeur (2000), de "innovación semántica."

Por lo tanto, la noción de imaginación puede ayudarnos a discernir los cambios en el campo religioso así como seguramente en otros. Lejos de presentarse de una forma asistemática, el imaginario puede mostrar una disposición sui generis. En especial, atendiendo a las formas en las que las categorías de segundo orden se expresan en los símbolos, entendidos en clave geertziana, y en los discursos emergentes en los contextos rituales que participan a los actores. La imaginación permite dilucidar cómo se pergeñan e implementan

\footnotetext{
En este sentido, Jean-Paul Willaime (1996, p. 50-51) afirma que uno de los aspectos en los que la modernidad se ha manifestado con mayor énfasis es en “una individuación cada vez mayor que ‘emancipa’ al individuo de los constreñimientos comunitarios (la familia, el pueblo, la parroquia, el sindicato, el partido político, etcétera) y en una desacralización de las instituciones-magisterios que pretenden imponer sus normas (Iglesia, ejército, escuela, etcétera)”.
} 
transformaciones colectivas deseadas, y donde valoraciones ordenadas colaboran en pensar una totalidad a partir de secciones que se visualizan como primordiales.

En paralelo a este orden simbólico hubo igualmente una solidaridad de sentido en la construcción de esas valoraciones. Los significados compartidos en torno al monacato imaginado, presuponían la convergencia de voluntades que concurrían en acciones concretas. No obstante, las tensiones fueron inevitables en el montaje de una empresa alternativa a la de los religiosos que abrazaron las misiones más allá del monasterio. En términos conceptuales, hay un peligro en la utilización de la idea de imaginación en presuponer linealmente una "comunidad de imagen" equiparable a una "comunidad moral" (Durkheim, 1993, p. 98). Es decir, asumir que los miembros de un colectivo social generan idénticas representaciones respecto de un proyecto imaginado. Es prudente tomar una distancia de Durkheim en esta dimensión para contemplar los conflictos de la imaginación que monjes y meditadores nos revelan.

Si es legítima la pregunta que formula Crapanzano (2005, p. 367) acerca de si "[s]omos vítimas de uma epistemologia puritana da presença” - de la creencia y de la práctica, retomando el problema inicial de este artículo-, probablemente la imaginación nos muestre una entrada a lo que no es evidente a los ojos y que está más allá de las ideas y las acciones que las sustentan. Naturalmente, es necesario aclarar, la imaginación no puede explicar todos los fenómenos sociales. Como cualquier otro esquema de teoría, la imaginación tiene su propio ámbito de aplicación, el cual, me atrevería a decir por su carácter procesual -como es apreciado por Turner (1974)-, está dado por la invención y el cambio religioso o de otro género. Estos procesos, por su condición liminar, son avenidas hacia formas sociales alternativas. Lo contrario de la imaginación es la reproducción; y se presenta de forma infrecuente en la experiencia social. Parecería ser que los límites de la imaginación están dados por la rutinización como por la normalización. Sin embargo, si aceptamos el cambio como accesorio habitual del ciclo diario y componente integral de sociedades que son regularmente cambiantes, permisas que por fuerza deben dejar un amplio lugar a la historia, la imaginación se vuelve constitutiva del cotidiano y no ya de hitos extraordinarios o mudanzas trascendentes. Estas últimas son sólo situaciones extremas de la imaginación, cuyos ejemplos bien se ilustran en los estudios de Anderson (2000) y Appadurai (1996). Es precisamente en las expectativas, miedos, deseos y experiencias individuales y 
colectivas, tanto pasadas como presentes, donde surgen las imágenes que se ensayan en la vida real.

Es en la vivencia compartida de estos experimentos sociales, en los que concurren invenciones colectivas, transformaciones e imaginación, donde se perfilan las líneas directrices de lo que serían formaciones sociológicas más o menos estables -aunque definitivamente no estáticas- en el tiempo. Como corolario, pueden establecerse tres problemas medulares que debería afrontar una teoría de la imaginación: 1) quiénes son -en términos sociológicos- los sujetos de la imaginación (e.g., instituciones, grupos, colectividades, etc.), y cuáles sus relaciones con otros y entre ellos mismos; 2) cuál es el objeto de la imaginación y cuál la composición del espacio semántico en el que se inserta (i.e., deseos, expectativas, sentimientos, historia, etc.); y, 3) a través de qué procedimientos aquél objeto se torna operativamente imaginable y realizable. El ejemplo estudiado permite sostener que esto resulta de una deconstrucción fragmentada de lo que es imaginado, tal como se ve en la proliferación de imágenes que surgen del relevamiento etnográfico. La imagen tiene el poder de la evocación; evocación de algo que no está pero que debería estarlo deseablemente en un presente o en un futuro mediato o inmediato y, en ocasiones, también en un pasado. Es en la función proyectiva que caracteriza a la imaginación donde radica el gen que motoriza la acción orientada a la mutación social.

\section{Referencias}

ANDERSON, B. R. Comunidades imaginadas: reflexiones sobre el origen y la difusión del nacionalismo. Buenos Aires: Fondo de Cultura Económica, 2000.

APPADURAI, A. Theory in anthropology: center and periphery. Comparative Studies in Society and History, Cambridge, v. 28, n. 2, p. 356-361, Apr. 1986.

APPADURAI, A. Modernity at large: cultural dimensions of globalization. Minneapolis: University of Minnesota Press, 1996.

BACHELARD, G. La poética del espacio. Buenos Aires: Fondo de Cultura Económica, 2000.

BACZKO, B. Los imaginarios sociales: memorias y esperanzas colectivas. Buenos Aires: Nueva Visión, 1999. 
BAKHTIN, M. M. The dialogic imagination. Austin: University of Texas Press, 1981.

BHABHA, H. K. El lugar de la cultura. Buenos Aires: Manatial, 2002.

CAROZZI, M. J. Creencias: lo que no es cuerpo para las ciencias sociales de la religión. Religião e Sociedade, Rio de Janeiro, n. 22, p. 57-76, 2002.

CASTORIADIS, C. Hecho y por hacer: pensar la imaginación: encrucijadas del laberinto V. Buenos Aires: Eudeba, 1998.

CASTORIADIS, C. La institución imaginaria de la sociedad. Buenos Aires: Tusquets, 2007.

CERIANI CERNADAS, C. Nuestros hermanos Lamanitas: indios y fronteras en la imaginación mormona. Buenos Aires: Biblos, 2008.

COMAROFF, J.; COMAROFF, J. Ethnography and the historical imagination. Boulder: Westview Press, 1992.

COMAROFF, J.; COMAROFF, J. Civil society and the political imagination in Africa. Chicago: Chicago University Press, 2000.

CRAPANZANO, V. Horizontes imaginativos e o aquém e além. Revista de Antropologia, São Paulo, n. 48, p. 363-384, 2005.

DURAND, G. La imaginación simbólica. Buenos Aires: Amorrortu, 1971.

DURKHEIM, E. Las formas elementales de la vida religiosa: el sistema totémico en Australia. Madrid: Alianza, 1993.

GARCÍA CANCLINI, N. Imaginarios urbanos. Buenos Aires: Eudeba, 1997.

GEERTZ, C. La interpretación de las culturas. Barcelona: Gedisa, 1987.

HALL, S. Blue election, election blues. Marxism Today, London, p. 30-35, July. 1987.

HILL, M. The religious order: a study in virtuoso religion and its legitimation in the nineteenth-century Church of England. London: Heinemann Educational Books, 1973. 
JAMESON, F. Imaginary and symbolic in Lacan: Marxism, psychoanalytic criticism, and the problem of the subject. Yale French Studies, New Haven, n. 55/56, p. 338-395, 1977.

LE GOFF, J. El orden de la memoria: el tiempo como imaginario. Barcelona: Paidós, 1991.

LÉVI-STRAUSS, C. El pensamiento salvaje. México: Fondo de Cultura Económica, 1988.

LUDUEÑA, G. A. Tradition and imagination in the creation of a new monastic model in contemporary Hispanic America. International Journal for the Study of the Christian Church, London, n. 8, p. 43-55, 2008.

LUDUEÑA, G. A. La 'cultura católica’ en la imaginación política de las iglesias latinoamericanas. In: STEIL, C. A.; MARTÍN, E.; CAMURÇA, M. (Org.). Religiones y culturas: perspectivas latinoamericanas. Buenos Aires: Biblos, 2009. p. 115-154.

LUDUEÑA, G. A. Localidad, modernidad y performance misional en la migración de religiosos católicos a la Argentina a comienzos del siglo XX. Relaciones: Estudios de Historia y Sociedad, Michoacán, v. 31, n. 124, p. 91-121, 2010.

MIGNOLO, W. Local histories/global designs: coloniality, subaltern knowledges, and border thinking. Princeton: Princenton University Press, 2010.

RIBEIRO, G. L.; ESCOBAR, A. (Org.). Antropologías del mundo: transformaciones disciplinarias dentro de sistemas de poder. Popayán: CIESAS-Envión Editores, 2008.

RICOEUR, P. La metáfora viva. Madrid: Ediciones Europa, 1980.

RICOEUR, P. Ideología y utopía. Barcelona: Gedisa, 1994.

RICOEUR, P. Del texto a la acción: ensayos de hermenéutica II. Buenos Aires: Fondo de Cultura Económica, 2000.

ROSE, A. M. Varieties of sociological imagination. American Sociological Review, Washington, v. 34, n. 5, p. 623-630, Oct. 1969. 
SÁENZ, P. Diálogo del silencio: monjes en la Iglesia de hoy. Buenos Aires: Latinoamérica Libros, 1967.

SAID, E. Orientalismo. Buenos Aires: Debolsillo, 2005.

SARLO, B. La imaginación técnica: sueños modernos de la cultura argentina. Buenos Aires: Nueva Visión, 1992.

SARTRE, J.-P. La imaginación. Buenos Aires: Sudamericana, 1973.

SILBER, I. F. Virtuosity, charisma, and social order: a comparative sociological study of monasticism in Theravada Buddhism and medieval Catholicism. Cambridge: Cambridge University Press, 1995.

TAMBIAH, S. J. World conqueror and world renouncer: a study of Buddhism and polity in Thailand against a historical background. Cambridge: Cambridge University Press, 1977.

TAMBIAH, S. J. The renouncer: his individuality and his community. In: MADAN, T. N. (Org.). Way of life: king, householder, renouncer: essays in honor of Louis Dumont. New Delhi: Vikas Publishing House, 1982. p. 299-320.

TURNER, V. W. Dramas, fields, and metaphors: symbolic action in human society. New York: Cornell University Press, 1974.

WEBER, M. Economía y sociedad: esbozo de sociología compresiva. México: Fondo de Cultura Económica, 1996.

WILLAIME, J.-P. Dinámica religiosa y modernidad. In: GIMÉNEZ, G. (Org.). Identidades religiosas y sociales en México. México: UNAM, 1996. p. 47-65.

WRIGHT MILLS, C. La imaginación sociológica. México: Fondo de Cultura Económica, 1961. 